\title{
Determination of phenol compounds in waste water by using compelling agent: $\mathrm{N}$-Phenyl-benzoic-hydroxamic acid
}

\author{
Deepak Kumar Yadav ${ }^{1}$, Jeena Harjit ${ }^{2}$ \\ ' (Ph.D scholar, MEWAR university Gangrar, Chittorhgarh, Rajasthan, \\ ${ }^{2}$ (Ph.D Supervisor , Department of Engineering Chemistry, Truba Institute of Engineering and Information \\ Technology, Bhopal,M.P.
}

\begin{abstract}
This research studies in detail the contents of phenolic compound by complexing with N-Phenylbenzo-hydroxamic acid, carried out by spectrophotometric method. The waste samples were collected from Mandideep industrial area of Bhopal .Phenols can be detected at wavelength between 505-522nm immediately after mixing N-Phenyl-benzo-hydroxamic acid with vanadium $(V)$ in acidic medium, without heating, in buffer medium. This results in the formation of reddish violet to violet coloured complexes in chloroform. By variation of $\mathrm{pH}$, temperature, time, concentration of reagent, an optional system for determination of phenols in waste water was found. The results showed that phenols concentration had an excellent linear relationship over a range of 0.00010-0.00110, 0.000122-0.00122, 0.000113-0.00113, and 0.000128-0.00128 $\mu \mathrm{g} / \mathrm{ml}$, Sandells sensitivity $1.0 \times 10^{-6}, 1.1 \times 10^{-6}, 1.0 \times 10^{-6}$ and $1.2 \times 10^{-6}$, relative standard deviation $1.37 \%, 1.91 \%, 1.47 \%$ and1.13\%,molar absorptivity $9.090 \times 10^{5}, 8.216 \times 10^{5}, 8.849 \times 10^{5}$ and $7.812 \times 10^{5}$ for $\alpha$-naphthol, $\beta$-naphthol, $p$ aminophenol and resorcinol, respectively. The method is found to be very sensitive, stable, reproducible, rapid , easy to be applied and not expensive.
\end{abstract}

Key words: chloroform, reproducible, sensitive, $N$-Phenyl-benzo-hydroxamic acid .

\section{Introduction}

Phenols are important industrial chemicals of environmental concern since they are involved in many industries such as coke, refineries, manufacture of resin, pharmaceuticals, pesticides and can also occur in waste water. Presence of phenolic compounds even at low concentration in industrial waste water adversely affect aquatic as well as human life directly or indirectly. Phenolic compounds are present in the environment as a result of their uses and the processes in which they are implicated. Although they can be originated naturally due to the degradation of humic substances, tannins and lignins, many industrial processes (including production of drugs, textiles, dyes, pesticides and paper) [1-6]. Phenols are toxic and potentially carcinogenic and can affect the taste and odor of drinking water with concentrations as low as a few $\mu \mathrm{gL}^{-1}$. Chronic toxicity of phenol in humans result in headache, vomiting, difficulty in swallowing, liver injury, fainting ,etc. As a consequence, both, the US Environmental Protection Agency (EPA) and the European Union (EU) have included some phenols, mainly chlorophenols and nitrophenols, in their lists of priority pollutants . EU Directive 2455/2001/EC sets a maximum concentration of $0.5 \mu \mathrm{gL}^{-1}$ in drinking water and their individual concentration should not exceed $0.1 \mu \mathrm{gL} \mathrm{L}^{-1}$.

Analytical techniques commonly used in the determination of phenols are high-performance liquid chromatography (HPLC)[7] and capillary electrophoresis (CE) in combination with ultraviolet detection (UV), electrochemical detection or mass spectrometry detection (MS). Liquid chromatography of phenols is generally carried out with the addition of acids or buffers to the mobile phase [8,9]. Their function is to suppress the ionization of both, the analytes and the residual silanols of the stationary phase base material, which otherwise would either decrease retention on the analytical column or lead to interactions of the analytes and the stationary phase, resulting in lower separation efficiencies. Also, gas chromatography (GC)[10], using several detection methods like flame ionization detection (FID), electron-capture detection (ECD) or mass spectroscopy detection (MS), incineration[11],chemical oxidation[12],photo oxidation[13],free cultured biological degradation[14,15],enzymatic treatment [16],adsorption[17] and membrane separation[18,19] have been used, although in the case of GC, a derivatization step is needed [20]. Nevertheless, the detection limits imposed by environmental quality legislation can only be achieved by using appropriate sample preparation techniques, which provide high enrichment factors of these analytes. Current official analytical methods for phenolic compounds extraction are liquid liquid extraction (LLE), (US EPA Methods 604, 605, 8041)[21] for liquid samples, and Sox let extraction, for solid samples[22] . These methods require expensive and hazardous organic solvents, which are undesirable for health and disposal reasons, and they involve a long time per analysis. Various spectrophotometric methods have also been reported for the determination of phenol . The most common reagent used are 4-aminoantipyrine [23,24], Gibb's reagent [25] , 2, 4-nitrophenylhydrazine [26] . For 
these reasons, these traditional sample methods have been replaced for other methodologies which are more sensitive, selective, fast and environmental friendly.

In the present work, a detailed study of determination of different phenolic compounds in industrial waste water has been highlighted .The profile of four phenols, $\alpha$-naphthol, $\beta$-naphthol, $\mathrm{p}$-aminophenol and resorcinol in industrial waste water is reported .

\section{Experimental}

2.1 Instrument : SHIMADZU Spectrophotometer 1700" model was used for electronic spectral measurement with $10 \mathrm{~mm}$ matched quartz cell. A Hanno 8521 model $\mathrm{pH}$ meter was also used.

2.2 Reagents: All the chemicals used were of AR grade. All standard and sample solutions were made up with double distilled water.

2.3 Preparation of solutions: Stock phenolic solutions were prepared by dissolving $0.1 \mathrm{gm}$ of accurately weighed phenolic contents in $100 \mathrm{ml}$ freshly boiled and cooled distilled water. From this solution standard solutions were prepared by appropriate dilution with same type of water. Buffer solution with $\mathrm{pH}=10$ for phenols, was prepared by dissolving $70 \mathrm{gm} \mathrm{NH}_{4} \mathrm{Cl}$ in water and adding suitable amount of $\mathrm{NH}_{4} \mathrm{OH}$ in 1lt distilled water. N-Phenylbenzo-hydroxamic acid solution was prepared by dissolving $0.1 \mathrm{gm}$ in $100 \mathrm{ml}$ distilled water. Phenol-PBHA complex was extracted in chloroform .4M hydrochloric acid solution was used to provide acidic medium.

2.4 Procedure : The calibration curve was obtained by following method - It is done with a semi-micro burette. $1 \mathrm{ml}$ of each standard phenol solution ( $\alpha$-naphthol, $\beta$-naphthol, p-amino phenol and resorcinol) containing $0.00010-0.00110,0.000122-0.00122,0.000113-0.00113$, and $0.000128-0.00128 \mu \mathrm{g} / \mathrm{ml}$, respectively were transferred to a series of $25 \mathrm{ml}$ calibrating flask.This was followed by addition of $10 \mathrm{ml}$ of buffer solution, $1 \mathrm{ml}$ of N-Phenyl-benzo-hydroxamic acid in chloroform , $1 \mathrm{ml}$ Vanadium(V) solution and $1 \mathrm{ml} 4 \mathrm{M} \mathrm{HCl}$ solution. Voilet to reddish voilet colour was obtained. The absorbance was measured at $513 \mathrm{~nm}, 510 \mathrm{~nm}, 505 \mathrm{~nm}$ and $522 \mathrm{~nm}$ for $\alpha$-naphthol, $\beta$-naphthol, p-aminophenol and resorcinol, respectively against reagent blank. Colour, Beer's law range, molar absorptivity,standard deviation, relative standard deviation and sandell's sensitivity are given in table-1.

Table : 1 Parameters of N-PBHA and phenolic complexes

\begin{tabular}{|c|l|c|c|c|c|}
\hline S.No. & Parameters & $\alpha$-naphthol & $\beta$-naphthol & p-aminophenol & Resorcinol \\
\hline 1 & Colour & Purple & $\begin{array}{c}\text { Reddish } \\
\text { purple }\end{array}$ & Reddish purple & Purple \\
\hline 2 & $\lambda_{\max }(\mathrm{nm})$ & 513 & 510 & 505 & 522 \\
\hline 3 & Beer's law range $\left(\mu \mathrm{g} \mathrm{mL}^{-1}\right)$ & $\begin{array}{c}0.00010- \\
0.00110\end{array}$ & $\begin{array}{c}0.000122- \\
0.00122\end{array}$ & $\begin{array}{c}0.000113- \\
0.00113\end{array}$ & $\begin{array}{c}0.000128- \\
0.00128\end{array}$ \\
\hline 4 & $\begin{array}{l}\text { Molar Absorptivity }\left(\mathrm{L} \mathrm{Mole}^{-1}\right. \\
\left.\mathrm{cm}^{-1}\right)\end{array}$ & $9.090 \mathrm{X} 10^{5}$ & $8.216 \times 10^{5}$ & $8.849 \times 10^{5}$ & $7.812 \times 10^{5}$ \\
\hline 5 & Standard deviation \pm & 0.005856 & 0.006782 & 0.006715 & 0.004112 \\
\hline 6 & Relative standard deviation $(\%)$ & 1.37 & 1.91 & 1.47 & 1.13 \\
\hline 7 & Sandell's sensitivity $\left(\mu \mathrm{g} / \mathrm{cm}^{2}\right)$ & $1.0 \mathrm{X} 10^{-6}$ & $1.1 \mathrm{X} 10^{-6}$ & $1.0 \mathrm{X} 10^{-6}$ & $1.2 \times 10^{-6}$ \\
\hline
\end{tabular}

III. Expected Reaction : (3.1) for $\alpha$-naphthol

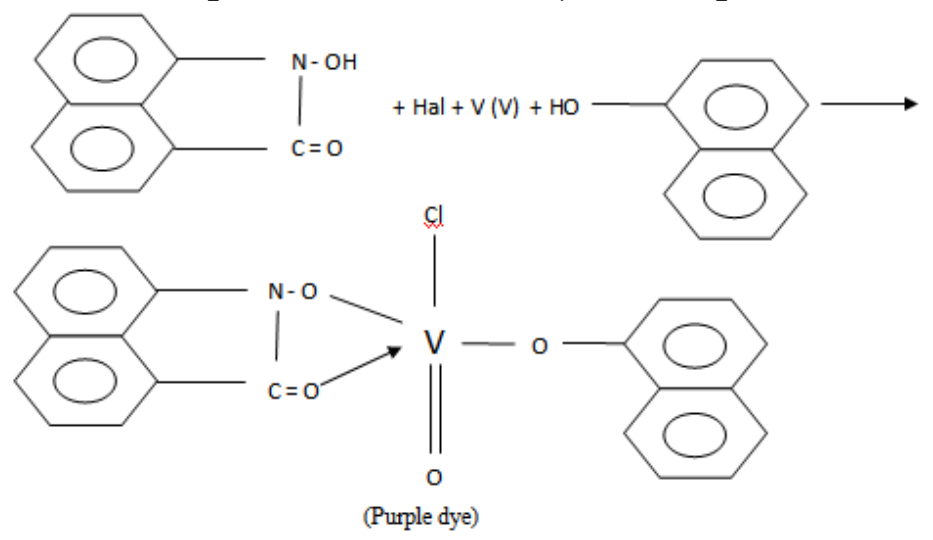


(3.2) for $\beta$-naphtha

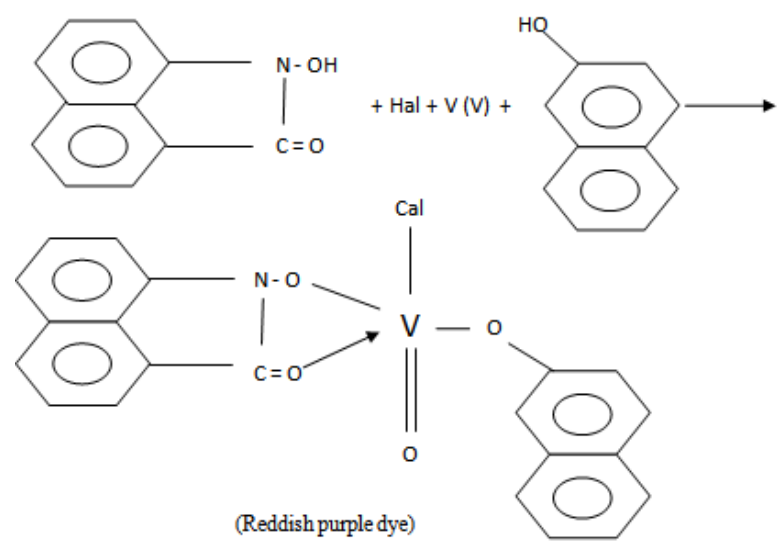

(3.3) for p-amino phenol
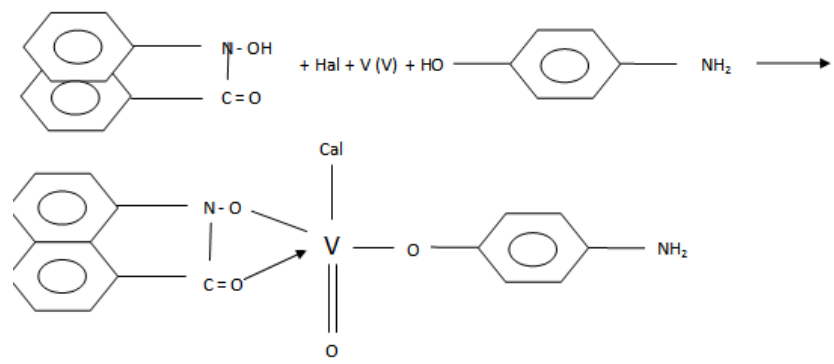

Reddish purple dye)

(3.4) for Resorcinol

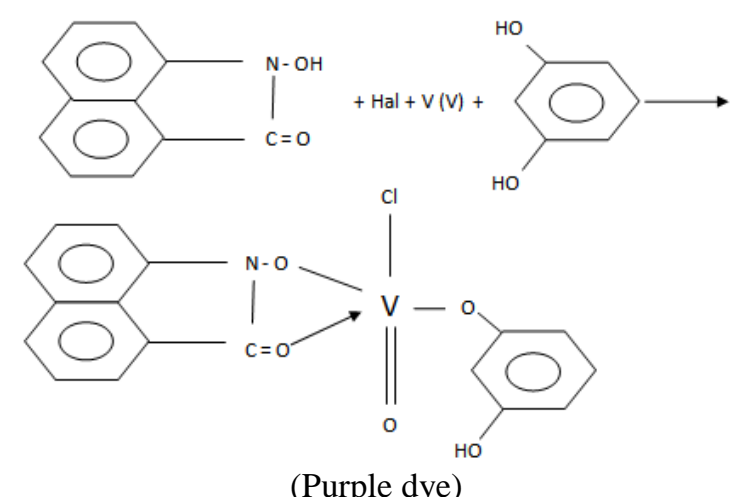

IV. Result and Discussion

Significant differences in result existed by using different solvents. Table 2 shows that N PBHA has highest solubility in chloroform where as water resulted in lowest value .

Table : 2 Solubility of N-PBHA in various solvents

\begin{tabular}{|c|l|c|}
\hline S.No. & Solvents & Solubility $(\boldsymbol{\mu g} / \mathbf{m l})$ \\
\hline 1. & Water & 0.02 \\
\hline 2. & n-Hexane & 0.03 \\
\hline 3. & Cyclohexane & 0.08 \\
\hline 4. & Carbon tetrachloride & 0.16 \\
\hline 5. & Benzene & 1.66 \\
\hline 6. & Toluene & 0.29 \\
\hline 7. & o-Dichlorobenzene & 2.50 \\
\hline 8. & Chlorobenzene & 2.70 \\
\hline 9. & Chloroform & 2.86 \\
\hline
\end{tabular}

1.1 Absorption spectrum and calibration curve : After reaction, complex present in organic phase was scanned from $400 \mathrm{~nm}$ to $600 \mathrm{~nm}$ against reagent blank (Figure-1) Maximum absorption values were observed at 513, 510 
,505 and 522nm for $\alpha$-naphthol, $\beta$-naphthol, p-amino phenol and resorcinol ,respectively with N-PBHA. Thus, these were selected for absorption measurement throughout the experiments.

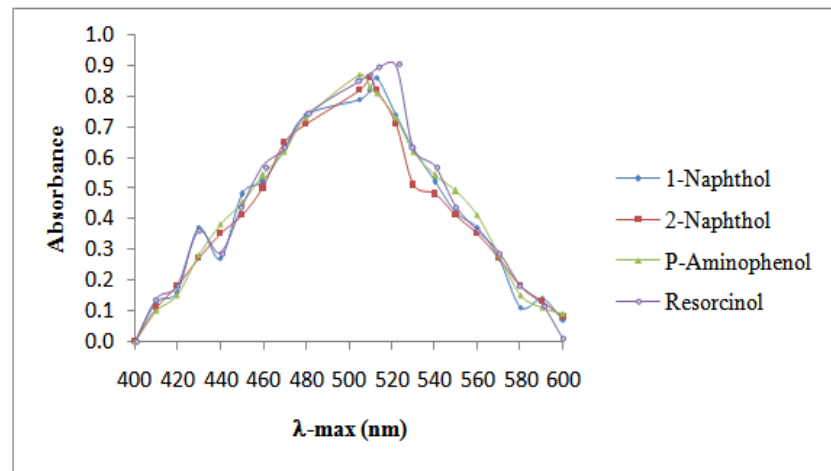

Fig.-1 Absorption spectra of phenolic complexes with N-PBHA.

Calibration plot of absorbance against concentration of phenolic contents at absorption maxima gave linear and reproducible graph in the concentration range of $0.00010-0.00110,0.000122-0.00122,0.000113$ 0.00113 , and $0.000128-0.00128 \mu \mathrm{g} / \mathrm{ml}$ for the four phenols. The calibration curve is shown in Figure 2.1-2.4.

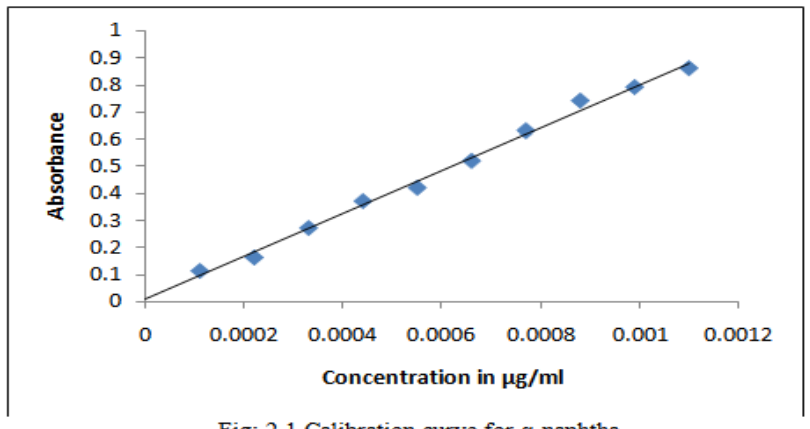

Fig: 2.1 Calibration curve for $\alpha$-naphtha

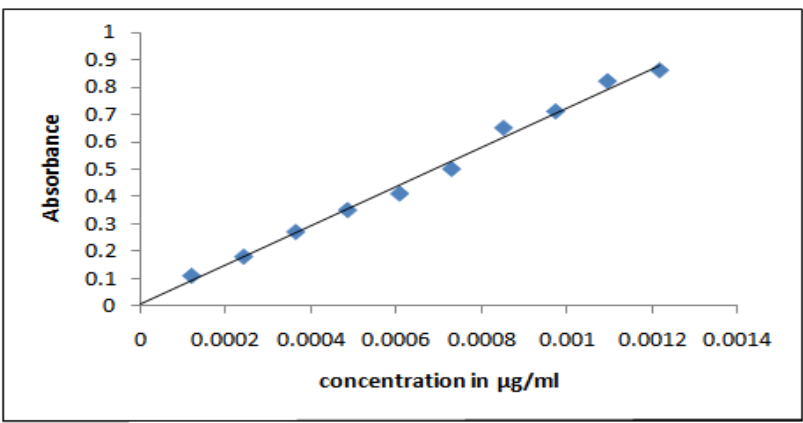

Fig: 2.2 Calibration curve for $\beta$-naphthol

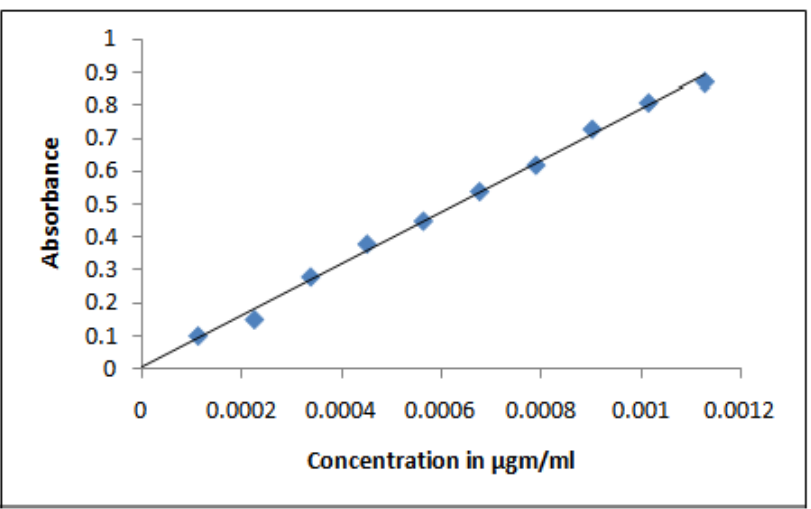

Fig: 2.3 Calibration curve for p-aminophenol 


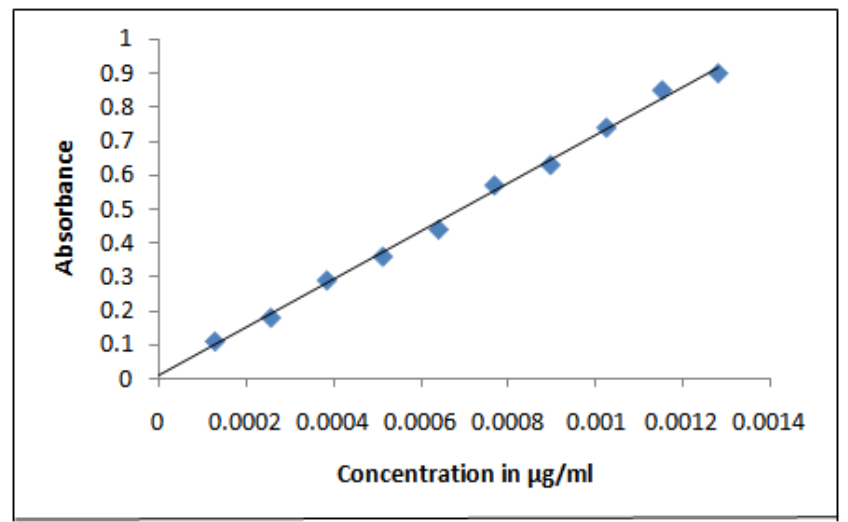

Fig: 2.4 Calibration curve for resorcinol

1.2 Effect of reagent concentration : The amount of N-PBHA was varied for determining its optimal concentration to a series of $1 \mathrm{ml}$ of phenolic contents, varying concentration of N-PBHA was added. It was observed that by increasing the concentration of hydroxamic acid absorbance increases and with $1 \mathrm{ml} 0.0001 \%$ $\mathrm{N}$-PBHA solution, it reaches maximum absorption. When the concentration was further increased there was no change .(Figure-3)

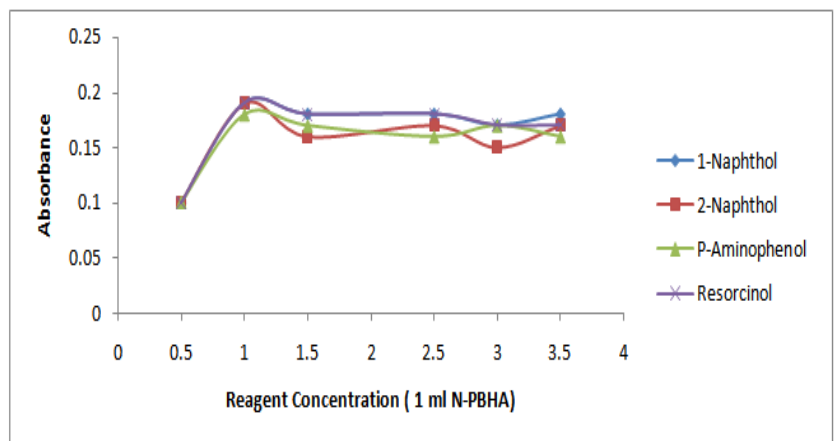

Fig.3 : Effect of reagent concentration

4.3 Effect of time and temperature: The effect of temperature on colour stability and absorbance of the complex was studied over the temperature range of $10^{\circ}$ to $50^{\circ} \mathrm{C}$. Room temperature $\left(25^{\circ} \mathrm{C}\right)$ was found to be most suitable.On increasing temperature reaction stability and absorbance of complex decreases . Thus, all experiment were performed at room temperature. The colour developed immediately after addition of reactants and remained stable for several days.

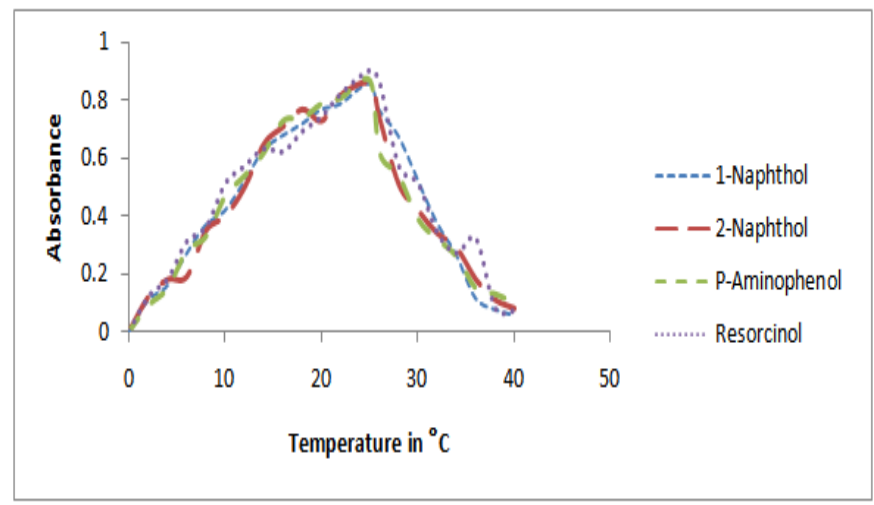

Fig.4 : Effect of temperature

4.4 Effect of $\mathrm{pH}$ : Optimum condition was measured of $\mathrm{pH}$ range $1.0-10$, most effective result were obtained at $\mathrm{pH}-4$. Most effective result were obtained by using $4 \mathrm{M}$. Increase or decrease in molarity results in fading of colour. This is shown in figure 5 . 


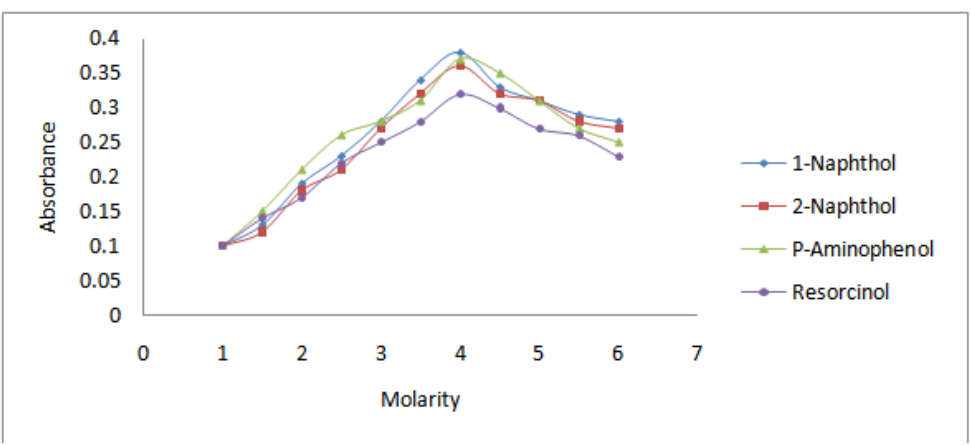

Fig. 5 : Effect of molarity of acid

4.5 Order of addition of reagent : The order followed was - standard phenol solutions, PBHA solutionin chloroform, $\mathrm{V}(\mathrm{V})$ saturated solution, $\mathrm{HCl}$ solution followed by distilled water. If the order is changed sensitivity decreases.

4.6 Effect of foreign species - To check the validity of the method, effects of several species commonly found along with phenol solution on the reaction were studied. This was done by addition of known amount of these species to $3 \mu \mathrm{g}$ phenol prior to its analysis by the proposed method. The tolerance limits for various interfering species are shown in table : 3 Tolerance level $\left(\mu \mathrm{g} \mathrm{mL}^{-1}\right)$

Table : 3 Effect diverse ions on the determination of phenolic contents by N-PBHA

\begin{tabular}{|c|c|c|c|c|}
\hline \multirow{2}{*}{ Foreign Species } & \multicolumn{4}{|c|}{ Tolerance level $\left(\mu \mathrm{g} \mathrm{mL}^{-1}\right)$} \\
\hline & $\alpha$-Naphthol & $\beta$-Naphthol & P-Aminophenol & Resorcinol \\
\hline Methenol, Ethenol ,Benzene & 970 & 990 & 990 & 970 \\
\hline Toluene & 300 & 280 & 290 & 280 \\
\hline Formaldehyde, aniline & 290 & 290 & 300 & 280 \\
\hline o-nitrophenol & 80 & 70 & 70 & 60 \\
\hline o-cresol, p-cresol, m-cresol & 770 & 760 & 760 & 780 \\
\hline $\mathrm{Hg}^{2+}, \mathrm{Ca}^{2+}, \mathrm{Pb}^{2+}$ & 790 & 790 & 780 & 770 \\
\hline $\mathrm{Al}^{3+}, \mathrm{Fe}^{3+}$ & 1160 & 1150 & 1170 & 1160 \\
\hline $\mathrm{PO}^{4-}, \mathrm{SO}^{4-}, \mathrm{CH}_{3} \mathrm{COO}$ & 1370 & 1360 & 1350 & 1370 \\
\hline $\mathrm{S}^{2-}$ & 80 & 100 & 80 & 90 \\
\hline
\end{tabular}

\section{Application}

In order to evaluate the analytical application of the method it was used for determination of phenolic contents in industrial waste water of Mandideep industrial area (Bhopal). For analysis of real samples, some pretreatment is necessary. All suspended particles should be removed by suitable procedures . Centrifugation was done. The samples were transferred in calibration flask and $0.5 \mathrm{ml}$ of $0.2 \mathrm{~mol}^{-1}$ EDTA was added as masking agent and then the procedure reported was applied .The results are given in Table -4 .

Table : 4 Phenolic contents in waste water

\begin{tabular}{|l|c|c|c|c|}
\hline Samples collection site & \multicolumn{4}{|c|}{ Amount of phenol found in $\left(\mu \mathrm{g} \mathrm{mL}^{-1}\right)$} \\
\hline & $\alpha$-Naphthol & $\beta$-Naphthol & $\mathrm{p}$-Aminophenol & Resorcinol \\
\hline W 1 Satlapur & 0.92 & 0.78 & 0.68 & 0.96 \\
\hline W 2 Khanpura & 1.23 & 1.07 & 1.06 & 1.16 \\
\hline W 3 Moizpura & 1.18 & 1.11 & 1.29 & 1.36 \\
\hline W 4 sarakia & 2.88 & 2.39 & 2.21 & 0.09 \\
\hline W 5 Jhalarkalan & 3.41 & 3.24 & 2.98 & 3.16 \\
\hline W 6 Nayapura & 3.27 & 3.39 & 2.89 & \\
\hline
\end{tabular}

\section{Conclusion}

Phenolic contents can be selectively detected by spectrophotometric method with PBHA. The reaction appeared to be quite universal since all the phenols related spontaneously with absorption maximum around $500 \mathrm{~nm}$. Thus, this wavelength was of the choice for characterisation of phenols. The reaction appeared to be very sensitive and therefore it might also be used as target analysis of phenols in complex matrices . it is also extended to the determination of phenolic contents in waste water of Mandideep area ,Bhopal. 


\section{Acknowledgement}

The authors are thankful to Director, Mewar University, Director, Truba Institute of Engineering and Information Technology and Principal ,Truba Institute of Pharmacy, for providing necessary facilities during research activity.

\section{References}

[1]. Sally N. Jabrou, Research Journal of Chemical Sciences, Vol. 2(4), (2012) 1-12.

[2]. Jens C. Frisvad Jorn Smedsgaard Thomas O. Larsen and Robert A. Samson, Studies in Mycology 49 : (2004), 201-241

[3]. J. Michałowicz, W. Duda, Polish, J. of Environ. Stud. Vol. 16, No. 3, (2007), 347-362

[4]. Yonca Yuzugullu, Zumrut Begum Ogel, Ufuk Bakir Bolukbasi, Nursen Coruh, Gurkan Karakas, Turk J Biol 35 , (2011), $697-704$

[5]. Divya N. Shetty, B. Narayana and S. Samshuddin, Journal of Chemical and Pharmaceutical Research, 4(3), (2012), 1647-1653

[6]. Okuda, T., Ito, H. Molecules, 16, ( 2011), 2191-2217

[7]. Yongsoon Chung, Bull. Korean Chem. Soc., Vol. 26, No. 2: (2005), 297-302

[8]. M. Amzad Hossain and S. M. Salehuddin, As. J. Energy Env., 10(03), (2009), 176-184

[9]. Cristina Mahugo Santana, Zoraida Sosa Ferrera, and José J. Santana Rodríguez,Journal of Chromatographic Science, Vol. 43, (2005), 282-288

[10]. Zhong WenJue, Wang DongHong, XU XiaoWei, Wang BingYi, Luo Qian Senthil Kumaran Satyanarayanan \& Wang ZiJian,Chinese science bulletin Vol.56 No.3, (2011), 275-284

[11]. Wyasu G. and O. A. Kure, Advances in Applied Science Research, 3 (3), (2012), 1691-1701

[12]. Pradeep N V, Anupama, U.S.Hampannavar, Journal of Environment and Earth Science Vol 2, No.1, (2012), 2224-3216

[13]. Amir Hossein Mahvi, Afshin Maleki, Mahmood Alimohamadi and Azar Ghasri, Korean J. Chem. Eng., 24(1), (2007), 79-82

[14]. Akbar Esmaeili, Sharouz Fazeli, Rom. J. Biochem., 49, 2, (2012), 153-161

[15]. S. Chakraborty, T. Bhattacharya, T.N. Patel and K.K. Tiwari, Journal of Environmental Biology, 31, ( 2010), $293-296$

[16]. Hejri S., Saboora A. JSUT 35 (1), (2009),. 13-19

[17]. Jolanta Bohdziewicz, Gabriela Kaminska, Malwina Tytla, Architecture Civil Engineering Environment (2), (2012), 89-94

[18]. Ompe Aime Mudimu, Martin Peters, Florian Brauner and Gerd Braun, American Journal of Environmental Sciences 8 (3), (2012), 195-201

[19]. S. Datta, P.K. Bhattacharya, N. Verma, Journal of Membrane Science 226 , (2003), 185-201

[20]. Hart, A.P.; Dasgupta, A. J. Forensic Sci. 42, (1997), 693-696

[21]. N.N.Rao, Jai Ram Singh, Rohit Mishra and T. Nandy Journal of Scientific and Industrial research vol 68, (2009), 823-828

[22]. Lolita Tomsone, Zanda Kruma, Ruta Galoburda, World Academy of Science, Engineering and Technology Vol:64 (2012)

[23]. Hussain J. Mohammed , Hayfaa J. Mohammed \& Huda S. Hassen, The Islamic University Journal ,Vol.17, No.1, (2009), 25-35

[24]. Theia'a N. Al-Sabha, Pak. J. Anal. Environ. Chem. Vol. 11(1), (2010)

[25]. Usra. I. S. Al-Neaimy, J. Edu. \& Sci., Vol. (22), No.4 (2009)

[26]. Padmarajaiah Nagaraja and Ashwinee Kumar Shreshtha, E-Journal of Chemistry , 7(2), (2010), 395-402 